\title{
Study of Oligohydramnios and its perinatal outcome
}

\author{
Sudha V. Patil ${ }^{1 *}$, Fatima Zahra Shaikmohammed ${ }^{2}$
}

\begin{abstract}
${ }^{1}$ Department of Obstetrics and Gynecology, Akash Institute of Medical Sciences and Research Centre, Devanahalli Bangalore Rural, Karnataka, India

${ }^{2}$ Department of Obstetrics and Gynecology, SVS Medical College and Research Centre Mahabubnagar, Hyderabad, Telangana, India
\end{abstract}

Received: 17 April 2019

Revised: 13 May 2019

Accepted: 30 May 2019

\section{*Correspondence:}

Dr. Sudha V. Patil,

E-mail: sudhavpatil@gmail.com

Copyright: ( $)$ the author(s), publisher and licensee Medip Academy. This is an open-access article distributed under the terms of the Creative Commons Attribution Non-Commercial License, which permits unrestricted non-commercial

\section{ABSTRACT}

Background: Importance of amniotic fluid volume as an indicator of fetal status is being appreciated relatively recently. Around $3 \%$ to $8 \%$ of pregnant women are presenting with low amniotic fluid at any point of pregnancy. The present study was undertaken to study the outcome of pregnancies with Oligohydramnios [(amniotic fluid index) $\mathrm{AFI} \leq 5 \mathrm{~cm}]$ at or beyond 34 weeks.

Methods: This study consists of 50 cases of antenatal patients with oligohydramnios (AFI $\leq 5)$ at or beyond 34 weeks of gestation compared with age and gestation matched 50 normal liquor $(\mathrm{AFI} \geq 5$ and $\leq 25)$. The outcome measures recorded were labor, gestational age at delivery, amniotic fluid index (AFI), mode of delivery, indication for cesarean section or instrumental delivery, APGAR score and birth weight.

Results: In the present study, AFI was significantly decreased in cases $(3.74 \pm 1.2)$ compared $(12.54 \pm 2.5)$ with controls. Variable deceleration was noted in $14(28 \%)$ and late deceleration in $5(10 \%)$ cases. In control group, 2 (4\%) had late deceleration. In cases induced labor is in $14(28 \%)$, spontaneous labor $36(72 \%)$. In cases, term normal vaginal delivery was in $15(30 \%)$, PVD in $6(12 \%)$, LSCS in $28(56 \%)$ and instrumental vaginal delivery in $1(2 \%)$. In controls, full term normal vaginal delivery was in 41 (82\%), PVD in $5(10 \%)$, LSCS in $4(8 \%)$. APGAR score $<7$ at 1 minute was in $19(38 \%)$ and at 5 minutes was in $5(10 \%)$ in cases. Birth weight is reduced in cases. IUGR was reported in $9(18 \%)$ in cases.

Conclusions: Pregnancies with Oligohydramnios $(\mathrm{AFI} \leq 5)$ is associated with increased rate of non-reactive NST. Routine induction of labor for Oligohydramnios is not recommended. It is preferable to allow patients to go into spontaneous labor with continuous FHR monitoring. Antepartum diagnosis of Oligohydramnios warrants close fetal surveillance.

Keywords: Amniotic fluid index, APGAR score, Fetal heart rate, Intra uterine growth restriction, Non stress test

\section{INTRODUCTION}

Importance of amniotic fluid volume as an indicator of fetal status is appreciated all along. ${ }^{1}$ Normally during third trimester, around $3 \%$ to $8 \%$ of pregnant women are with low amniotic fluid at any point of pregnancy. It is normally anticipated as a sign of placental insufficiency. ${ }^{2}$ Most severe and frequent complication of pregnancy is
Oligohydramnios and the incidence of this is observed to be about $1-5 \%$ of total pregnancies. ${ }^{3}$

Amniotic fluid has a number of important roles in embryo/fetal development. It cushions that fetus against trauma, has antibacterial property and promotes growth and development of gastrointestinal and musculoskeletal system. ${ }^{2}$ It helps to maintain the fetal body temperature 
and plays a part in homeostasis of fluid, and permits fetal movements. ${ }^{4,5}$ Amniotic fluid volume maintains amniotic fluid pressure thereby reducing the loss of lung fluid- an essential component to pulmonary development. It prevents compression of the umbilical cord. ${ }^{6}$ Decreased amniotic fluid volume is frequently one of the first clues to an underlying fetal abnormality or maternal disease state. A significant reduction in the amniotic fluid correlates with an increased rate of both perinatal morbidity and mortality. ${ }^{7}$

Associate congenital fetal abnormalities with oligohydramnios are uteroplacental insufficiency, premature rupture of membranes, growth retardation, postterm pregnancy, chronic abruption placentae. ${ }^{8}$

Before the advent of ultrasound, clinicians had to rely on abdominal palpitation and fundal height measurements to detect abnormal fluid volume. The progressive improvements in ultrasonographic imaging have taken the technology of fetal and amniotic fluid assessment from the stage of subjective impression to present state in which relatively sophisticated judgment of fetal condition can be based on reproducible measurements. In present practice, semi quantitative amniotic fluid volume assessment during routine ultrasound examination and ante partum testing has become standard of care.

Most common quantitative measure used in clinical practice is AFI. It is calculated by dividing the uterus externally into 4 quadrants and using ultrasound to measure vertical diameter of the largest pocket in each quadrants and using ultrasound to measure vertical diameter of the largest pocket in each quadrant in millimeter, which is then summed to calculate AFI. ${ }^{9}$ $\mathrm{AFI} \leq 5 \mathrm{~cm}$ is the accepted cut off for the diagnosis of Oligohydramnios. Ante partum diagnosis of Oligohydramnios by means of AFI accounted for $2.3 \%$ of pregnancies undergoing sonography after 34 weeks. ${ }^{10}$

Sonogram- assisted diagnosis of Oligohydramnios is associated with increased pregnancy intervention, still birth, fetal heart rate deceleration during labor and increased neonatal morbidity and mortality. ${ }^{10}$ Oligohydramnios can be an idiopathic finding in women who have low risk pregnancies and no medical or fetal complication. ${ }^{11}$ The present study was undertaken to study the outcome of pregnancies with Oligohydramnios $(\mathrm{AFI} \leq 5 \mathrm{~cm})$ at or beyond 34 weeks.

\section{METHODS}

This prospective study was done at Department of Obstetrics and Gynecology, SVS Medical College, Mehaboobnagar, Telangana. This study consists of 50 cases of antenatal patients with the ultrasound diagnosis of oligohydramnios $(\mathrm{AFI} \leq 5)$ at or beyond 34 weeks of gestation compared with 50 normal liquor (AFI $\geq 5$ and $\leq 25$ ) and matched for age, parity and gestational age. The subjects with congenital anomaly, ruptured membranes, port term pregnancies, pregnancy induced hypertension, multiple pregnancies were excluded from the study. Informed consent was obtained from the study subjects. The study was approved by the institutional ethics committee.

All the pregnant women in the study who went into spontaneous labor were allowed to deliver irrespective of gestational age with continuous fetal heart rate monitoring. Caesarean delivery or instrumental vaginal delivery were performed in these women for nonreassuring fetal heart pattern during labor. Women not in labor with the gestational age between 34-37 weeks were closely monitored with biweekly NST and biophysical profile (BPP), until they went into spontaneous labor. If they fail to go into spontaneous labor, they were induced at term with dinoprostone get $(0.5 \mathrm{~mL})$ or oxytocin drip depending on the Bishop's score. Cesarean delivery or instrumental vaginal delivery were performed in these women for non-reassuring fetal heart rate pattern during labor. Women with mal presentation and other obstetric indications were directly taken for cesarean delivery.

NST/Admission test was done for all subjects. Variable deceleration was considered significant if it was below $70 \mathrm{bpm}$ persisting for 60 seconds. Those who developed significant variable, repetitive late deceleration or other ominous FHR pattern with or without meconium stained liquor which persisted in spite of corrective measures like change in maternal position, hydration, $\mathrm{O}_{2}$ inhalation and stopping oxytocin were diagnosed as fetal distress and delivered by LSCS or by instrumental vaginal delivery. For all newborns endotracheal intubations were in presence of meconium stained amniotic fluid.

The outcome measures recorded were labor, gestational age at delivery, amniotic fluid index (AFI), FHR tracing, mode of delivery, indication for cesarean section ot instrumental delivery, APGAR score at 1 minute and 5 minutes, birth weight.

\section{RESULTS}

The present study included 100 pregnant women. Among them 50 were cases of oligohydramnios $(\mathrm{AFI} \leq 5)$ at or beyond 34 weeks of gestation and 50 were 50 normal liquor $(\mathrm{AFI} \geq 5$ and $\leq 25)$ and matched for age, parity and gestational age. Age and gestational ages were not significant between cases and controls. Amniotic fluid index (AFI) was significantly decreased in cases (3.74 \pm 1.2$)$ compared $(12.54 \pm 2.5)$ with controls as illustrated in Table 1.

As shown in Table 2, variable deceleration was noted in $14(28 \%)$ and late deceleration in $5(10 \%)$ cases. In control group no women developed variable deceleration and $2(4 \%)$ had late deceleration. In cases induced labor is in $14(28 \%)$ and spontaneous labor is in $36(72 \%)$. In cases, full term normal vaginal delivery was in $15(30 \%)$, PVD in $6(12 \%)$, LSCS in $28(56 \%)$ and instrumental 
vaginal delivery in $1(2 \%)$. In controls, full term normal vaginal delivery was in $41(82 \%)$, PVD in $5(10 \%)$, LSCS in $4(8 \%)$ and instrumental vaginal delivery nil.

Table 1: Demographic representation of the subjects.

\begin{tabular}{|lll|}
\hline & Study group $(n=50)$ Mean \pm SD & Control group $(n=50)$ Mean \pm SD \\
\hline Age & $22.3 \pm 3.97$ & $22.6 \pm 3.9$ \\
\hline Gestational age & $38.1 \pm 2.3$ & $37.2 \pm 1.9$ \\
\hline AFI & $3.74 \pm 1.2$ & $12.54 \pm 2.5^{*}$ \\
\hline
\end{tabular}

* Significant $(\mathrm{p}<0.05)$.

Table 2: Occurrence of variable and late deceleration, labor, mode of delivery between cases and controls.

\begin{tabular}{|lll|}
\hline FHR pattern & Cases & Controls \\
\hline Variable deceleration & Number (\%) & Number (\%) \\
\hline Late deceleration & $14(28 \%)$ & 0 \\
\hline Induced labour & $5(10 \%)$ & $2(4 \%)$ \\
\hline Spontaneous labour & $14(28 \%)$ & $1(2 \%)$ \\
\hline Full term normal vaginal delivery & $36(72 \%)$ & $49(98 \%)$ \\
\hline PVD & $15(30 \%)$ & $41(82 \%)$ \\
\hline LSCS & $6(12 \%)$ & $5(10 \%)$ \\
\hline Instrumental vaginal delivery & $28(56 \%)$ & $4(8 \%)$ \\
\hline
\end{tabular}

Table 3: APGAR score, birth weight and IUGR.

\begin{tabular}{|lll|}
\hline APGAR score & Cases & Controls \\
\hline 1 Minute $(<7)$ & Number $(\boldsymbol{\%})$ & Number (\%) \\
\hline 5 Minute $(<7)$ & $19(38 \%)$ & $13(26 \%)$ \\
\hline Weight $(\mathbf{k g})$ & $5(10 \%)$ & $2(4 \%)$ \\
\hline$<2.5$ & & $12(24 \%)$ \\
\hline$>2.6$ & $31(62 \%)$ & $38(76 \%)$ \\
\hline IUGR & $19(38 \%)$ & $1(2 \%)$ \\
\hline
\end{tabular}

As shown in Table 3, APGAR score measured $<7$ at 1 minute was in $19(38 \%)$ and at 5 minutes was in $5(10 \%)$ in cases and in controls APGAR score at 1 minute was in $13(26 \%)$ and at 5 minutes was in $2(4 \%)$. In cases, birth weight is $<2.5 \mathrm{kgs}$ was in $31(62 \%)$ and $>2.5$ was in 19 $(38 \%)$ and in controls, < $2.5 \mathrm{kgs}$ was in $12(24 \%)$ and $>2.5 \mathrm{kgs}$ was in $38(76 \%)$. IUGR was reported in $9(18 \%)$ in cases and $1(2 \%)$ in controls.

\section{DISCUSSION}

Amniotic fluid volume is now recognized as an important marker of fetal well being. In the present study, the amniotic fluid volume was assessed by ultrasonography using amniotic fluid index. The mean age of the study group in the present study was 22.6 years which is comparable with Elizabeth $\mathrm{G}$ et al, and Casey BM et al. ${ }^{10,12}$ The mean gestational age in the present study was 38.1 weeks comparable with 37.5 years in a study by Casey BM et al. ${ }^{10}$ The mean AFI in the present study was
$3.74 \mathrm{~cm}$ comparable with a study by Elizabeth $\mathrm{G}$ et al of $3.2 \mathrm{~cm} .{ }^{12}$ Occurrence of meconium stained amniotic fluid was not more in women with Oligohydramnios. Meconium stained liquor was noted in $22 \%$ in the present study. This is consistent with studies by Locatelli A et al. ${ }^{13}$

Because of the fear of poor pregnancy outcome if the women with Oligohydramnios remained undelivered, there is increased incidence of induction of labor in the Oligohydramnios group. In the present study, 14 (28\%) study group were induced. In a study by Casey et al, the rate of induction was $42 \%$, Rainford et al, it was as high as $98 \%$ and Kreiser et al, reported that $7 \% .{ }^{10,14,15}$ There is increased incidence of caesarean delivery in Oligohydramnios. This increased incidence is due to increased induction of labor leading to fetal distress.

In the present study, $56 \%$ of women underwent caesarean delivery. LSCS for fetal distress was done for $36 \%, 8 \%$ 
for IUGR, $12 \%$ for other inductions like $4 \%$ breech presentation, $4 \%$ for CPD, $2 \%$ for persistent occipito posterior, $2 \%$ for women with two previous LSCS.

APGAR score $<7$ at 5 minutes was $10 \%$ in the study group. Casey et al, found no difference in incidence of low APAGR score at 5 minutes $(<7) .{ }^{10}$ The rates of low Apgar score were similar between the pregnancies in study and control group. Our study results were consistent with Rainfor et al, Kreiser D et al, Locatelli et al, and Elizabeth $\mathrm{G}$ et al. ${ }^{12-15}$

Birth weights were significantly less in newborns with Oligohydramnios. The mean birth weight was $2.401 \mathrm{~kg}$ in the present study. The occurrence of low birth weight babies $<2.5 \mathrm{~kg}$ was $62 \%$ which is comparable with other studies like Chandra $\mathrm{P}$ et al, and Sriya $\mathrm{R}$ et al. ${ }^{16,17}$ The occurrence of low birth weight babies were significantly high even in women with term gestation. The incidence of IUGR is significantly increased in patient with Oligohydramnios. In the present study, the rate of occurrence of IUGR was $18 \%$.

\section{CONCLUSION}

Pregnancies with Oligohydramnios $(\mathrm{AFI} \leq 5)$ at or beyond 34 weeks is associated with increased rate of non reactive NST. FHR deceleration during labor, development tof fetal distress, rate of caesarean delivery and low birth weight. Rate of caesarean for fetal distress is increased because of increased rate of induction of labor in the women with Oligohydramnios. Routine induction of labor for Oligohydramnios is not recommended. No appropriate route of delivery can be recommended by this study. It is preferable to allow patients to go into spontaneous labor with continuous fetal heart rate monitoring. Termination of pregnancy with Oligohydramnios by caesarean delivery or instrumental vaginal delivery to be done at the onset of fetal distress. Antepartum diagnosis of Oligohydramnios warrants close fetal surveillance.

\section{Funding: No funding sources}

Conflict of interest: None declared

Ethical approval: The study was approved by the Institutional Ethics Committee

\section{REFERENCES}

1. Chamberlain MB, Manning FA, Morrison I. Ultrasound evaluation of amniotic fluid index, the relationship of marginal and decreased amniotic fluid volume to perinatal outcome. Am J Obst Gynecol. 1984;150:2459.

2. Gaikwad PR, Oswal MS, Gandhewar MR, Bhatiyani BR. Perinatal outcome in oligohydramnios and borderline amniotic fluid index: a comparative study. Int J Reprod Contracept Obstet Gynecol. 2016;5:19648.

3. Moore TR. Clinical assessment of amniotic fluid. Clin Obstet Gynaecol. 1997;40(2):303-13.

4. Brace RA. Physiology of amniotic fluid volume regulation. Clin Obstet Gynecol. 1997;40:280-9.

5. Wallenburg HCS. The amniotic fluid. Water and electrolyte homeostasis. J Perinat Med. 1977;5:193.

6. Nicolini U, Fisk NM, Rodeck CH, Talbert DG, Wigglesorth JS. Low amniotic pressure in oligohydraminos is the cause of pulmonary hypoplasia. Am J Obstet Gynecol. 1989;161:1098-101.

7. Lyndon M, Hill MD. Oligohydraminos: Sonographic diagnosis and clinical implications. Clin Obstet Gynecol. 1997;40(2):314-27.

8. Bansal D, Deodhar P. A clinical study of maternal and perinatal outcome in oligohydramnios. J Res Med Den Sci. 2015;3(4):312-6.

9. Ott WJ. Re-evaluation of the relationship between amniotic fluid volume and perinatal outcome. Am J Obstet Gynecol. 2004;192:1803-9.

10. Casey BM, Mc Intire DD, Donald D. Pregnancy outcome after diagnosis of oligohydraminos at or beyond 34 weeks gestation. Am J Obstet Gynecol. 2000;182:902-9012.

11. Leeman L, Almond D. Isolated oligohydraminos at term: is induction indicated? J Fam Pract. 2005;54:2532.

12. Elizabeth G, Voxman, Susan T, Deborah A. Wing. Low amniotic fluid index as a predictor of adverse perinatal outcome. J Perinatol. 2002;22:282-5.

13. Locatelli A, Vergani P, Toso L, Verderio M, Pezzullo JC, Ghidini A. Perinatal outcome associated with oligohydraminos in uncomplicated term pregnancies. Arch Gynecol Obsted. 2004;269(2):130-3.

14. Rainfor M, Adair R, Scialli AR, Ghindini A, Spong CY. Amniotic fluid index in the uncomplicated term pregnancy: prediction of outcome. J Repro Med. 2001;46(6):589-92.

15. Kreiser D, EI-Sayed YY, Sorem KA, Chitkara U, Holbrook RH, Druzin ML. Decreased amniotic fluid index in low risk pregnancy. $\mathrm{J}$ Reprod Med. 2001;46(8):743-6.

16. Chandra P, Kaur SP, Hans DK, Kapila AK. The impact of amniotic fluid assessed intrapartum on perinatal outcome. Obstet Gunae Today. 2000;5(8):478-81.

17. Sriya R. Singhai S, Rajan M, Sharma M, Nagpal P. Perinatal outcome in patients with amniotic fluid index $\leq 5 \mathrm{~cm}$. J Obstet Gynecol India. 2001;51(5):98-100.

Cite this article as: Patil SV, Shaikmohammed FZ. Study of Oligohydramnios and its perinatal outcome. Int J Reprod Contracept Obstet Gynecol 2019;8:2705-8. 